\title{
Absenteeism among female pluckers in a tea plantation in south India
}

\author{
Kumara RP ${ }^{1}$, Fathima FN ${ }^{2}$, Fernandes $\mathbf{S}^{3}$, Xavier $\mathbf{V}^{3}$, Ramesh $\mathbf{N}^{4}$ \\ ${ }^{1}$ Postgraduate, ${ }^{2}$ Associate Professor, ${ }^{3}$ Medical Interns, ${ }^{4}$ Associate Professor \\ Department of Community Health, St. John's Medical College, Bangalore 560034. India.
}

\section{ABSTRACT}

Background: The tea industry which is one of the world's oldest agro-based industry provides direct employment to more than a million workers, of which most are women. Two of the main causes for decreased tea production in India is due to shortage of pluckers and their absenteeism which impacts tea productivity. So, this study was undertaken to study absenteeism rates and the causes of absenteeism among female pluckers in a tea plantation in South India.

Methodology: This was a cross section study undertaken in tea estates located in Anamalais, Tamilnadu. All female pluckers working in the estates were eligible to part of the study. The study population consisted of 256 female tea pluckers who were selected at random and an interview schedule was used to collect the following information - socio-demographic status, nature of the job, job satisfaction and reasons for absenteeism.

Results: The study population consisted of $80.9 \%$ permanent workers and $19.1 \%$ temporary workers, with an average work experience of 21.6years. The main cause of absenteeism was health related (47.8\%), followed by visit to native place $(29.3 \%)$, then illness among family members $(15.7 \%)$ and either lazy of bored to report to work $(7.2 \%)$.There was an association between absenteeism and hospitalization in the past one year, increasing number of children in the family and the number of years of work experience.

Conclusion: Majority of the pluckers were in the age group of 40-45 years. Women in this age group are more vulnerable to health issues such as osteoporosis, osteoarthritis, work related musculoskeletal disorders and also probably time taken off to take care of dependents apart from house old chores. Increasing age, illness of self or family member were the most important factors which contributed to increase absenteeism.

Key words: Absenteeism, pluckers, tea plantations, causes, South India

DOI: https://doi.org/10.3126/ijosh.v9i2.25381

\section{Introduction}

India is the second largest producer and largest consumer of tea in the world. ${ }^{1,2}$ The tea industry which is one of the world's oldest agro-based industry provides direct employment to more than a million workers, of which most are women. The tea sector in the country is largely organized, in early 1990's, nearly $94 \%$ of India's tea was produced in organized sector which reduced to about $66 \%$ by $2017 .{ }^{1,2,3} \mathrm{As}$ of 2015 , 566.66 thousand hectares was under tea production

\section{Corresponding Author}

Dr. Naveen Ramesh

Associate Professor

Department of Community Health, St. John's Medical

College, Bangalore 560034. India.

E-mail: drnaveenr@gmail.com

ORCID ID: 0000-0001-5269-7186 in India and India's tea export was valued at United States Dollar 785.92 million. $^{3}$

Tea plantation labourers are paid as per the legal minimum wages announced by the respective state governments. Labourers are paid based on the time spent working and amount of tea plucked per day. In addition, the workers are given an incentive wage for plucking leaves above their fixed daily quota. The Indian tea industry provides direct employment to over 1 million people and another 10 million persons derive their livelihood from tea associated activities. ${ }^{4}$ Simply put, 1 out of 7 workers in the organised manufacturing sector works in tea sector. $4,5,6$

\section{(c) (i) (9)}

This journal is licensed under a Creative Commons AttributionNon Commercial 4.0 International License. 
Absenteeism is habitual non-presence of an employee at his or her job. Habitual non-presence is time away from work beyond the normal schedule. ${ }^{7}$ The Labour Department in India defined the absenteeism rate as the total man-shifts lost because of absences as a percentage of the total number of man-shifts scheduled. . $^{7,8,9}$

Absenteeism is a crisis and has a major impact on labour productivity in tea plantations. ${ }^{7,8}$ The management is forced to employ temporary labourers or migrant laborers due to absenteeism of seasoned workers and it results in decreased productivity and increased cost to the management.

The causes of absenteeism vary from place to place. They could be physical, psychosocial or environmental causes. The major causes of absenteeism apart from wages among the tea plantation labourers were illness in the worker or family member, alcoholism, workers morale, absence after social and cultural ceremonies and absence of adequate welfare facilities. . $^{9,10,11}$

The production of tea in India has come down in the recent years owing to several factors. Two of the maincauses for decreased production is labour shortage and absenteeism. There are very few studies done on absenteeism and its causes among tea plantation labourers in India and other countries. Through this study, we aim to measure absenteeism rate and determine the various causes of absenteeism. This will help to quantify the main reasons for absenteeism and thus to find a way to reduce the absenteeism rate in tea plantations. The objective was to study absenteeism rates and the causes of absenteeism among female pluckers in a tea plantation in South India.

\section{Methodology}

The study area consisted of tea estates in Anamalais, Tamilnadu. The tea estates had a total population of 2916. Majority of the tea leaf plucking population comprised of females and all female pluckers working in the estates were eligible to part of the study. Maintenance staffs, sundry workers and management were excluded from the study. The study design was cross-sectional. In the first step, duty rosters of the workers in plantation were reviewed since the past one month and absenteeism rate was measured. Absenteeism rate was calculated by using the formula:

Absenteeism rate $=$ Total number of man days lost $\mathrm{x}$ Total number of workers
Total number of working days $\mathrm{x}$ Total number of workers

Based on the previous study ${ }^{9}$, taking absolute precision to be $5 \%$ and $95 \%$ confidence interval, sample size was calculated to be 256 . Thelist of all female pluckers was procured from the estate management. Simple random sampling of the workers was done by computer generated random numbers. In case the individual fell into the exclusion criteria, the next person was selected. A pre-tested, structured interview was administered to 256 female pluckers. The interview schedule collected information regarding socio-demographic status, nature of the job, job satisfaction, reasons for absenteeism (owing to health and health associated factors, financial causes, domestic violence, laziness, social and cultural causes, etc.). Data were entered in Microsoft Excel and analysed by using Standard Statistical Software (SPSS version 16)for proportions, frequencies and associations. We considered $P$ value of less than 0.05 as significant.

\section{Results}

A total of 256 female pluckers were studied. The workforce consisted of $80.9 \%$ permanent workers and $19.1 \%$ temporary workers, with an average work experience of 21.6years. Most of them were in the age group of 43.38 years, with a standard deviation (SD) of 9.98 years. Majority of the pluckers lived in a nuclear families $(80.5 \%)$, followed by extended (16\%) and three generation families (3.5\%). Among the study population $98.5 \%$ were married, highest educational qualification attained by the pluckers was high school $(42.2 \%), \quad 25.8 \%$ were uneducated, the average household income was Rs.6283.20. Wage per day per person was Rs.210 (as the Minimum Wages Act). The pluckers spent 9 hours per day in plantation, with free time of 1 hour per working day. They had one holiday in a week, and bonus was availed by workers who had minimum one year experience. The socio demographic details and job profile of the study participants have been depicted in Table 1.

The hospital record review showed that the absenteeism rate is 4.19 person days per month. The absenteeism rate calculated after the interview revealed absenteeism rate to be 8.73person days per month. The total number of days absent was found to be 946 in the last month, with an inter-quartile range of $4(0,4)$. The mean number of days absent for the last month was 7.19 days with a SD of 1.33 days. 
Our study found that $35.5 \%$ of pluckers were absent for atleast one day in the last week, and $52.3 \%$ were absent for at least one day in the last month. The main cause of absenteeism was health related $(47.8 \%)$, with most of the workers complaining about back pain (3.1\%). Majority of workers fell ill at least two times per month, with $20.3 \%$ being admitted in the last 30 days to the hospital owing to health issues. Of the working population, $12.9 \%$ had chronic illnesses, the main being asthma (4.3\%). Pluckers also suffered from physical injuries at workplace making them take leaves for more than 2 days (11.3\%), of which most common was fracture. Among the injured, 28 people were compensated. About a third (29.3\%) took leave to visit native place once a year. Another cause for absenteeism was owing to a family member's ill health. Workers were absent for a mean of 6.35 days in a year due to family member's illness (15.7\%). Among the husbands of pluckers, $68.2 \%$ consume alcohol. However no physical abuse has been reported by the pluckers. Some pluckers $(7.2 \%)$ took leave for no reason or they were lazy or bored to report to

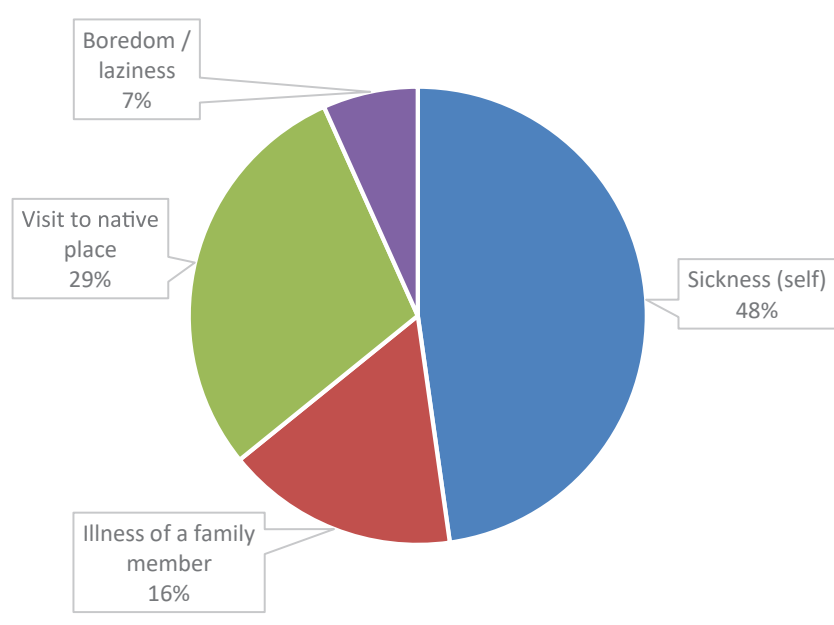

Figure 1: Causes of absenteeism in the study population work. The causes for absenteeism among the study participants are depicted in figure 1. The number of days of absenteeism was significantly higher among those who were hospitalized in the past one year (Chi square: 20.382 ; df- $3 ; p=0.000$ ). The number of days of absenteeism increased with the number of children in the family (Chi square: 12.731; $p=0.048$ ). We also found a positive correlation between absenteeism and the number of years of work experience $(r=0.04$, $p<0.05)$.

\section{Discussion}

In our study, we found that, most of the pluckers were in the age group of 40-45 years. This goes on to imply that majority of the women who were working belonged to older age group. This makes the women more vulnerable to health issues such as osteoporosis, osteoarthritis and so on. ${ }^{10,11,12}$ It also makes them more vulnerable to work related musculoskeletal disorders. ${ }^{13}$

Our study found that the monthly rate of absenteeism is $8.7 \%$. Another study, done in Mancotta gardens at Assam by Goswami et. al. ${ }^{12}$, found that the annual rate of absenteeism was $27.4 \%$ and monthly rate of absenteeism which is found to be $2.28 \%$. This higher rate of absenteeism may be due to better management and record keeping in the health care facilities in the estate where we conducted this study, as compared to Mancotta estates, where the absenteeism was mainly self -reported and record review was not done.

Our study also found an interesting point, which was that as the work experience increased, there was increased absenteeism in the plantation. This could be possibly due to higher age of the working population. In addition, the study participants had dual responsibilities in the form of household chores and care of dependents at home including children, grand children, elderly parents and in-laws.

Table 1: Sociodemographic details and job profile of the study particpants

\begin{tabular}{lc}
\hline Variable & \\
\hline Age & $43.3+9.9$ years \\
\hline Type of family & Nuclear $(80.5 \%)$ \\
\hline Marital status & Married $(98.5 \%)$ \\
\hline Highest Educational Qualification & High School $(42.2 \%)$ \\
\hline Average monthly household income & Rs. $6283.20 \pm 2137.57$ \\
Wages Per Day & Rs 210 \\
Working hours per day & 9 \\
Holidays per week & 1 \\
Mode of Travel to Work place & Walking \\
\hline
\end{tabular}


Our study found that the reported absenteeism rate was almost twice the rate documented in the hospital records. One reason for this could be error in recall. The under recording could also be because of study participants availing permissions to attend to personal work on an informal basis and not applying formal leave.

\section{Conclusion}

We conclude that the absenteeism rate among female pluckers in a tea plantation in South India is high. The main causes for absenteeism are increasing age, illness in self and among dependent family members.

\section{References}

1. India Brand Equity Foundation. Tea statistics[Internet]. India Brand Equity Foundation. 2019[Assessed on 2019/02/03]. Available on https:// www.teacoffeespiceofindia.com/tea/tea-statistics

2. Tea News. India records highest ever tea production during the financial year 2015-16; exports breach 230 million kgs mark after 35 years. India: Tea Boards India, Government of India; 2016[Assessed on 2019/02/03]. Available on http://www.teaboard. gov.in/TEABOARDPAGE/MTYx

3. Tea Board, Ministry of Commerce \&Industry Department of Commerce, Government of India. A paper on tea industry in the organised sector in India[Internet]. India:Ministry of Commerce \&Industry Department of Commerce, Government of India; 2017[Assessed on 2019/02/03].Available on http:// teaboard.gov.in/pdf/Press_Release_Paper_on_Tea_ Industry_pdf1181.pdf

4. Bhowmik SK. Productivity and Labour Standards in Tea Plantation Sector in India. Semantic Scholar[Internet]. 2003[Assessed on 2019/02/03]. Available on https://pdfs.semanticscholar.org/df8b/0 a545b76dec34a5f6bf5c0290172e03b0c00.pdf

5. Ministry of Agriculture, Government of India and Indian Institute of Foreign Trade. Tea Industry[Internet]. India: Ministry of Agriculture, Government of in India and Indian Institute of Foreign Trade. Available on http://agritrade.iift.ac.in/html/Training/ASEAN\%20 $\%$ E $2 \% 80 \% 93 \% 20$ India $\% 20$ F TA $\% 20 \% 20$ Emerging\%20lssues\%20for\%20Trade\%20in\%20 Agriculture/Tea\%20Export.pdf [cited on 03.02.2019].

6. Employment trends in Indian and Assam tea industry[Internet]. Available on http://shodhganga. inflibnet.ac.in/bitstream/10603/144423/9/ chapter\%20vii.pdf [cited on 03.02.2019].
7. Shah SK, Patel AV. Tea Production in India: Challenges and Opportunities, Journal of Tea Science Research. 2016;6(5):1-6.

8. Kenton W. Absenteeism. Investopedia. 2019 Jun 5(updated)[Assessed on 2019/07/01]. Available on https://www.investopedia.com/terms/a/absenteeism. asp

9. Basariya SR. Employee Absenteesim in Indian Industries. International Journal of Science and Research. 2015;4(10):141-56.

10. Mishra DK, Upadhyay V, Sarma A. 'Crisis' in the Tea Sector: A Study of Assam Tea Gardens. The Indian Economic Journal[Internet]. 2008;56(3):39-56[Assesses on: 2018/11/18]. Available on https://www.researchgate.net/ publication/284729349_'Crisis'_in_the_Tea_ Sector_A_Study_of_Assam_Tea_Gardens

11. Bose PR. Trouble's brewing in India's Tea Sector. The Hindu BusinessLine[Internet]. 2017 April 20[Assessed on 2018/11/18]. Available on https:// www.thehindubusinessline.com/opinion/troublesbrewing-in-indias-tea-sector/article21979485.ece

12. Goswami B. Absenteeism Among the Tea Garden Labourers: A case study on mancotta tea garden[Dissertation][Internet]. Dibrugarh, India: Dibrugarh Univeristy; 2009[Assessed on 2018/11/18]. Available on https://www.scribd.com/doc/62152741/ Absenteeism-Among-the-Tea-Garden-Labourers-Acase-study-on-mancotta-tea-garden

13. Vasanth D, Ramesh N, Fathima FN, Fernandez R, Jennifer S, Jospeph B. Prevalence, pattern, and factors associated with work-related musculoskeletal disorders among pluckers in a tea plantation in Tamil Nadu, India. IJOEM. 2015 Jan;26(3):167-70. 